\title{
Interacting Effects of Naltrexone and OPRMI and DATI Variation on the Neural Response to Alcohol Cues
}

\author{
Joseph P Schacht*,', Raymond F Anton', Konstantin E Voronin', Patrick K Randall', Xingbao Li', \\ Scott Henderson' and Hugh Myrick ${ }^{1,2}$ \\ 'Department of Psychiatry and Behavioral Sciences, Medical University of South Carolina, Charleston, SC, USA; ${ }^{2}$ Ralph H Johnson \\ VA Medical Center, Charleston, SC, USA
}

\begin{abstract}
Variation at a single nucleotide polymorphism in the $\mu$-opioid receptor gene (OPRM I), A I 8G (Asn40Asp), may moderate naltrexone (NTX) effects in alcohol dependence. Both NTX and AI I8G variation have also been reported to affect alcohol cue-elicited brain activation. This study investigated whether sub-acute NTX treatment and AII8G genotype interacted in their effects on cue-elicited activation of the ventral striatum (VS), medial prefrontal cortex (mPFC), and orbitofrontal cortex (OFC). Secondarily, variation at a variable number tandem repeat polymorphism in the dopamine transporter gene (DATI/SLC6A3), which has been associated with increased reward-related activation in VS, was analyzed as a moderator of medication and AII8G effects. Seventy-four non-treatmentseeking alcohol-dependent individuals, half preselected to carry at least one copy of the A I 8G G (Asp) allele, were randomized to NTX (50 mg) or placebo for 7 days, and performed an $\mathrm{fMRI}$ alcohol cue reactivity task on day 6. Region-of-interest analyses indicated no main effects of medication or A I I8G genotype. However, these factors interacted in their effects on OFC activation, such that, among NTXtreated individuals, G-allele carriers had less activation than A-allele homozygotes. DATI variation also moderated medication/AII8G effects. There was a three-way interaction between medication and AII8G and DATI genotypes on VS activation, such that, among G-allele carriers who received NTX, DATI I0-repeat-allele (IOR) homozygotes had less activation than 9-repeat-allele (9R) carriers. Further, IOR homozygotes who received NTX had less mPFC activation than 9R carriers. Polymorphic variation in OPRMI and DATI should be considered in future studies of NTX, particularly regarding its effects on reward processing. Neuropsychopharmacology (2013) 38, 4I4-422; doi:I0.1038/npp.2012.195; published online 3 October 2012
\end{abstract}

Keywords: alcoholism; opioid antagonist; functional neuroimaging; SNP; VNTR

\section{INTRODUCTION}

Naltrexone (NTX), an opioid antagonist with greatest affinity for $\mu$-opioid receptors, is a Food and Drug Administration-approved treatment for alcohol dependence that reduces heavy drinking and the likelihood of relapse (Kranzler and Van Kirk, 2001; Rosner et al, 2010). Its mechanism of action is believed to involve blockade of opioid-peptide-mediated disinhibition of dopaminergic afferents from the midbrain to the ventral striatum (VS; Benjamin et al, 1993). Dopamine (DA) release in VS underlies the acute pharmacological effects of alcohol (Yoshimoto et al, 1992), its reinforcing properties (Gonzales et al, 2004), and craving for it (Heinz et al, 2004). Accordingly, evidence suggests that NTX effects on drinking may be mediated through reduction of craving (Drobes et al, 2004; O'Malley et al, 2002) and/or alcoholinduced stimulation (Anton et al, 2004; Drobes et al, 2004).

*Correspondence: Dr JP Schacht, Department of Psychiatry and Behavioral Sciences, Center for Drug and Alcohol Programs, MSC 86I, Medical University of South Carolina, Charleston, SC 29425, USA, Tel: + I 843 792-7497, Fax: + I 843 792-7353, E-mail: schacht@musc.edu Received 25 July 2012; revised 23 August 2012; accepted 24 August 2012
Several studies have indicated that NTX efficacy may be moderated by variation at a non-synonymous single nucleotide polymorphism (SNP) in the first exon of the $\mu$-opioid receptor gene (OPRM1), A118G (also known as Asn40Asp; rs1799971; although this SNP is referred to in the literature, as well as in this manuscript, as A118G, this designation has been changed on the NCBI Human Genome Assembly to A355G (Asn102Asp), as recent evidence suggests that OPRM1 may contain 62 additional amino acids), such that NTX blunts alcohol-induced craving, stimulation, and subjective intoxication (Ray and Hutchison, 2007; Ray et al, 2012b) and reduces relapse rates (Anton et al, 2008; Chamorro et al, 2012; Oslin et al, 2003) to a greater extent among individuals who carry at least one copy of the $G$ allele. This allele, which encodes an asparagine (Asn) to aspartate (Asp) amino-acid substitution, has been reported to engender a threefold increase in $\beta$-endorphin-binding affinity for $\mu$-opioid receptors (Bond et al, 1998) and has been associated with reduced binding of ${ }^{[1(\mathrm{C})]}$-carfentanil, a selective $\mu$-opioid agonist (Weerts et al, 2012). However, it has also been associated with reduced OPRM1 mRNA and protein expression (Zhang et al, 2005), and some studies have reported no (Coller et al, 2011; Gelernter et al, 2007) or opposing (McGeary et al, 2006) interactions with NTX; 
hence, the SNP's functional relevance remains debated (Ray et al, 2012a). Nonetheless, the $\mathrm{G}$ allele has been associated with a variety of alcohol-related phenotypes, including greater alcohol-induced stimulation and craving (Ray and Hutchison, 2004) and, among non-human primates, greater preference for alcohol (Barr et al, 2010) and reduced alcohol-induced cortisol release (Schwandt et al, 2011).

Neuroimaging studies have also examined the effects of NTX and A118G genotype on alcohol-related phenotypes. NTX has been reported to reduce alcohol-cue-elicited activation of reward-related brain areas among nontreatment-seeking alcoholics, including the VS, medial prefrontal cortex (mPFC), and orbitofrontal cortex (OFC; Myrick et al, 2008), and to increase OFC activation during decision-making (Boettiger et al, 2009). A118G genotype has also been reported to affect alcohol cue processing; among heavy drinkers, G-allele carriers have demonstrated greater cue-elicited activation of VS, OFC, $\mathrm{mPFC} /$ anterior cingulate, inferior frontal gyrus, and claustrum than A-allele homozygotes (Filbey et al, 2008). Further, G-allele carriers have displayed enhanced striatal DA release in response to intravenously infused alcohol, paralleling a similar effect in mice expressing the human OPRM1 A118G variant (Ramchandani et al, 2011). However, no neuroimaging studies have examined whether NTX and A118G genotype interact in their effects on these phenotypes, perhaps due to the relative infrequency of the $G$ allele and the resultant difficulty in identifying and recruiting sufficient numbers of G-allele carriers for small-scale imaging studies.

The current study was designed to test this hypothesized NTX by A118G interaction with a sub-acute NTX treatment paradigm among non-treatment-seeking alcoholics prospectively recruited on the basis of their A118G genotype. We previously reported that this paradigm resulted in neither main effects of NTX or A118G genotype nor an interaction between these factors on drinking in the natural environment or in a bar laboratory (Anton et al, 2012). However, an exploratory analysis found a three-way interaction between NTX, A118G genotype, and variation at a 40-base-pair variable number tandem repeat (VNTR) in the $3^{\prime}$ untranslated region of the DA transporter gene (DAT1/SLC6A3) (rs28363170), such that, among NTXtreated subjects, A118G G-allele carriers who were also homozygous for the DAT1 10-repeat (10R) allele had reduced drinking relative to placebo, whereas A118G A-allele homozygotes who also carried the DAT1 9-repeat (9R) allele had greater drinking. The DAT1 9R allele has been associated with reduced DAT expression (Fuke et al, 2001; Mill et al, 2002; VanNess et al, 2005), and, among alcoholics, reduced striatal DAT availability (Heinz et al, 2000), suggesting that it may engender loss of DAT function and subsequent increases in synaptic DA accumulation. Further, in neuroimaging studies, this allele has repeatedly been associated with greater reward-related VS activation (Aarts et al, 2010; Dreher et al, 2009; Forbes et al, 2009; Franklin et al, 2009, 2011; Nikolova et al, 2011). As NTX effects are mediated through opioid-ergic mechanisms that influence striatal DA release, it was logical that a genetic variant that might engender greater striatal DA availability would moderate the NTX by A118G interaction. Thus, the current study also explored whether DAT1 VNTR variation moderated NTX or A118G effects on the neural response to alcohol cues.

\section{PATIENTS AND METHODS}

\section{Subjects}

Subjects were recruited via media advertisements and administered a brief phone screen to assess inclusion/ exclusion criteria. Two hundred and sixty-five individuals aged 21-65 years were screened for participation, of whom 83 were ultimately selected, on the basis of their OPRM1 A118G genotype and other variables of interest (see below). Subjects were required to self-identify as non-Hispanic $(N=76)$ or Hispanic $(N=2)$ White, Asian $(N=3)$, or Pacific Islander $(N=3)$, secondary to low A118G G-allele frequency among individuals of African descent. Subjects were also required to meet DSM-IV (Diagnostic and Statistical Manual of Mental Disorders, revised 4th edition; (American Psychiatric Association, 2000)) diagnostic criteria for current Alcohol Dependence, as assessed by the Structured Clinical Interview for DSM-IV (First et al, (2002)), and to deny currently seeking treatment for their alcohol use. Exclusion criteria were: current DSM-IV diagnosis of dependence on any substance except nicotine; use of any psychoactive medication or substance except nicotine or marijuana in the past 30 days, as evidenced by self-report and urine drug screen; current DSM-IV Axis I diagnosis or suicidal/homicidal ideation; history of significant medical illness; or liver enzymes $\geqslant 3$ times normal. Although recent marijuana use was not exclusionary, all subjects were required to have a negative urine drug screen for $\Delta^{9}$-tetrahydrocannabinol (cutoff: $50 \mathrm{ng} / \mathrm{ml}$ ) before beginning the study.

\section{Procedure}

The Medical University of South Carolina Institutional Review Board approved all procedures, and all subjects provided informed consent before participation, for which they were compensated. The study comprised four visits: a screening assessment; a follow-up assessment; the functional magnetic resonance imaging (fMRI) scan session; and a bar laboratory session. At the screening assessment, subjects provided a blood sample for A118G genotyping, after which all subjects with at least one copy of the $\mathrm{G}$ allele, and A-allele homozygotes who matched G-allele carriers on gender, smoking status, and family history of alcoholism (defined as having at least two biological first- or seconddegree relatives who subjects reported had a problem with drinking), were selected for participation and invited to return for the follow-up assessment. At this visit, subjects provided a urine sample for urine drug screen, completed the Alcohol Dependence Scale (ADS; Skinner and Allen, 1982) and Obsessive-Compulsive Drinking Scale (Anton et al, 1996), and were administered the Timeline Followback (Sobell and Sobell, 1992) to assess past-90-day drinking. Blood chemistry and a history and physical exam were also obtained at this visit.

Subjects were then randomized, on the basis of their A118G genotype, to receive either NTX or matched placebo for 7 days. All medications were administered in identical gel caps and blister-packed. Subjects were blind to their 
genotype group, and both subjects and investigators were blind to medication assignment. NTX was increased from $25 \mathrm{mg}$ on days 1 and 2 to $50 \mathrm{mg}$ on days 3-7. Subjects were given no explicit instructions about their drinking on days $1-5$ but were instructed to remain abstinent on the night of day 5 . On day 6 , subjects' drinking over the past 5 days was assessed with the Timeline Follow-back, and the fMRI scan occurred that afternoon. Subjects returned the following day for the bar lab session. Primary drinking outcomes, medication compliance, and results from the bar lab are reported elsewhere (Anton et al, 2012). There were no main effects or interactions of medication, A118G, or the DAT1 VNTR on drinking in the bar lab; hence, associations between bar lab results and imaging measures were not examined.

\section{Genotyping}

Complete details of the A118G and DAT1 VNTR assays, including quality control measures, are also reported in Anton et al (2012). Briefly, genomic DNA was extracted from peripheral blood mononuclear cells with a commercial DNA extraction kit (Gentra Puragene Blood Kit; Qiagen Inc., Valencia, CA) and amplified with a StepOne Real-Time PCR System (Applied Biosystems (ABI), Foster City, CA). For A118G genotyping, a Taqman $5^{\prime}$ nuclease assay (ABI), run with three known controls for each genotype, was used. For DAT1, custom primers 5'-TGT GGT GTA GGG AAC GGC CTG AG-3' and 5'-CTT CCT GGA GGT CAC GGC TCA AGG-3' (Invitrogen, Carlsbad, CA) were used for PCR amplification, amplified samples were electrophoresed on $2.0 \%$ agarose gels and visualized with ethidium bromide under ultraviolet light, and genotypes were scored by two raters independently.

\section{fMRI scan}

Of the 83 subjects randomized to medication, five did not undergo the fMRI scan: two secondary to claustrophobia; two because they had a breath alcohol level $>0$ on the scan day; and one because the scanner malfunctioned. fMRI procedures were identical to those previously published (Myrick et al, 2004, 2008, 2010; Schacht et al, 2011). Briefly, the remaining 78 subjects were first breathalyzed and evaluated with the Clinical Institute Withdrawal Assessment for Alcohol-Revised (CIWA-Ar; Sullivan et al, 1989); no subject had a breath alcohol level $>0$ or a CIWA-Ar score $>3$. After subjects were positioned in the scanner, a highresolution anatomical image for subsequent registration was acquired. Subjects were then given a sip $(10 \mathrm{ml})$ of their preferred 80-proof liquor mixed with fruit juice and administered a 720-s-long alcohol cue reactivity task consisting of 24 pseudorandomly interspersed blocks of alcoholic beverage images (ALC), non-alcoholic beverage images (BEV), blurred versions of both of these types of images that served as visual controls, and a fixation cross. Each 24-s-long block comprised only one type of picture and was followed by a 6-s washout period intended to allow the hemodynamic response from the previous block to decline before the next was presented. Images were selected from a normative set (Normative Appetitive Picture Set; Stritzke et al, 2004), supplemented with images from advertisements, and matched for intensity, color, and complexity. Alcohol image blocks were equally distributed between images of beer, wine, and liquor.

Functional images were acquired with gradient echo, echo-planar imaging sequences implemented on two $3 \mathrm{~T}$ scanners. The first 52 subjects' images were acquired with a Philips (Amsterdam, Netherlands) Interra scanner, and the last 26 subjects' images with a Siemens (Munich, Germany) TIM Trio. For the Philips scanner, the acquisition parameters were: repetition/echo times $(\mathrm{TR} / \mathrm{TE})=1853 / 30 \mathrm{~ms}$; 386 volumes; flip angle $(\mathrm{FA})=90^{\circ}$; field of view (FOV) $=208 \mathrm{~mm}$; matrix $=64 \times 64$; voxel size $=3.25 \times 3.25 \mathrm{~mm}$; and 36 contiguous $3.0-\mathrm{mm}$-thick transverse slices. For the Siemens scanner, the parameters were: TR/TE $=2200 / 35 \mathrm{~ms}$; 328 volumes; $\mathrm{FA}=90^{\circ} ; \mathrm{FOV}=192 \mathrm{~mm}$; matrix $=64 \times 64$; voxel size $=3.0 \times 3.0 \mathrm{~mm}$; and 36 contiguous $3.0-\mathrm{mm}$-thick transverse slices.

\section{Image preprocessing and regions of interest (ROIs)}

Of the 78 subjects scanned, four had unusable data, all of whom were scanned on the Philips scanner: one had $>2 \mathrm{~mm}$ translational motion; one fell asleep during the scan; one had corrupt files; and one dropped out of the study after the scan. The remaining 74 subjects' images were preprocessed with FSL v. 4.1.9 (Oxford Centre for Functional MRI of the Brain, Oxford, England; Smith et al, 2004). For each subject, images were realigned to the first volume, smoothed with an 8 - $\mathrm{mm}$ full-width-at-halfmaximum kernel, resampled to $2-\mathrm{mm}$ isotropic voxels, and registered, first to the subject's high-resolution anatomical image and subsequently to the Montreal Neurological Institute (MNI) 152-subject-average template.

ROIs were defined a priori as those regions in which more than one study had previously reported NTX or A118G main effects: VS, mPFC, and OFC. Each ROI was defined as a 6-mm-radius sphere with its center at the following points in MNI space: left VS, [ - 12, 6, - 9]; right VS, [12, 6, - 9]; mPFC, $[0,48,15]$; left OFC, [ $-22,24,-20]$; and right OFC, $[28,24,-20]$ (Figure 1). These points were based on the average of coordinates reported in previous NTX/A118G fMRI studies (Boettiger et al, 2009; Filbey et al, 2008; Myrick et al, 2008) and adjusted from these averages with the Harvard-Oxford cortical and subcortical brain atlases (http://www.cma.mgh.harvard.edu/fsl_atlas.html) to ensure all voxels within each ROI fell primarily within gray matter. ROIs were reverse-registered from the MNI-152 image to each subject's anatomical image, and the average timecourse of the blood-oxygen-level-dependent signal was extracted from all of the voxels in each ROI.

\section{Statistical analysis}

These ROI timecourses were then entered as the dependent variable in each of the five hierarchical linear models (HLMs) using HLM v. 6.0.8 (Scientific Software International, Skokie, IL). The order, onset, and duration of presentation of the cue reactivity task stimuli were entered as first-level independent variables in these models, as was the scanner (Philips or Siemens) and, to control for scanner-related variance in the magnitude of the outcome of interest, the interaction of scanner and the alcohol 


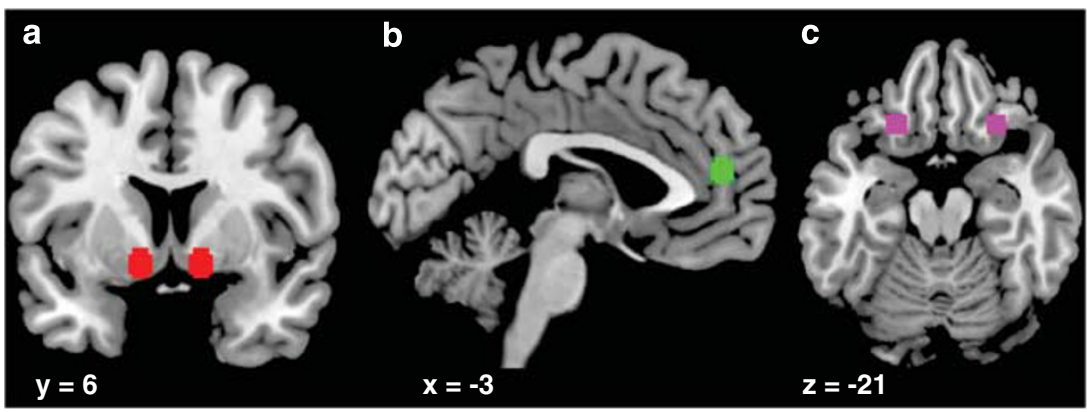

Figure I Regions of interest (ROIs) overlaid on the Montreal Neurological Institute (MNI) I52-subject-average brain template. (a) ventral striatum (VS); (b) medial prefrontal cortex (mPFC); (c) orbitofrontal cortex (OFC). Coordinates are in MNI space.

stimuli. Each HLM produced an estimate of blood-oxygenlevel-dependent activation in each ROI during alcohol stimuli relative to beverage stimuli (ie, ALC-BEV). Estimates for the left and right VS and for the left and right OFC were then averaged to yield three final outcome measures: VS, mPFC, and OFC ALC-BEV activation. Using SPSS v. 16.0 (IBM, Armonk, NY), each of these measures was entered as the dependent variable in a general linear model (GLM) that included medication, A118G genotype, and their interaction. Subjects' ages, ADS scores, and pre-study drinks/drinking day were covaried in these models. Exploratory GLMs with DAT1 VNTR genotype and all of its possible interactions with medication and A118G genotype, as well as the same covariates, were also run. To analyze the relationship between cue-elicited activation and drinking during the medication period, partial correlations were calculated across all subjects and within each medication/A118G group between activation in each ROI and drinks per day during the 5 days on medication, controlling for pre-study drinks/drinking day.

\section{RESULTS}

\section{Subject characteristics and genotype frequencies}

For the 74 subjects with usable scans, DAT1 VNTR genotypes and demographic and drinking data are presented by medication group and A118G genotype in Table 1 . Genotype frequencies for DAT1 were: 10R/10R, 0.66 $(N=49)$; 9R/10R, $0.27(N=20)$; and 9R/9R, $0.07(N=5)$. These frequencies were consistent with the expected frequencies for individuals of European and Asian descent (Kang et al, 1999) and in Hardy-Weinberg equilibrium. Frequencies for A118G were: A/A, $0.51(N=38) ; \mathrm{A} / \mathrm{G}, 0.43$ $(N=32)$; and $\mathrm{G} / \mathrm{G}, 0.05(N=4)$. For all analyses, for each variant, homozygous and heterozygous carriers of the minor allele (ie, the A118G G allele and DAT1 9R allele) were combined and compared with subjects homozygous for the major allele. There were no significant differences in medication or A118G group among subjects with $v s$ without usable scans $\left(\chi^{2}(3, N=83)=4.34, p=0.23\right)$. Subjects who received NTX were, on average, significantly older than those who received placebo $(t(59.6)=2.43, p=0.02$ (unequal variances (Welch's) $t$-test; age variance was significantly greater for the NTX group than the placebo group)), and A-allele homozygotes had significantly greater ADS scores than G-allele carriers $(t(72)=3.23, p=0.002)$; accordingly, as noted above, age and ADS score were covaried in all the analyses.

\section{NTX and A118G main effects and interaction}

There were no significant main effects of medication or A118G genotype on activation in any ROI. Neither age, ADS score, nor the scanner used significantly affected the magnitude of cue-elicited activation in any ROI. However, there was an interaction between medication and A118G genotype on $\mathrm{OFC}$ activation $(F(1,67)=4.38, p=0.04)$; among A-allele homozygotes, the simple effect of medication was significant $(F(1,67)=3.89, p=0.05)$, such that subjects who received NTX had greater activation than those who received placebo (Figure 2). Among subjects who received NTX, the simple effect of genotype approached significance $(F(1,67)=3.31, p=0.07)$, such that $\mathrm{G}$-allele carriers had less activation than A-allele homozygotes. This interaction was not significant for VS or MPFC activation.

\section{Correlations between brain activation and drinking}

For cue-elicited mPFC activation, the partial correlation with drinks per day during the 5 days on medication was not significant $(r(71)=0.18, p=0.14)$. Examination of this correlation within the medication and A118G subgroups revealed that it was significantly positive among G-allele carriers who received placebo $(r(15)=0.51, p=0.04)$, but not among those who received NTX, or among A-allele homozygotes, suggesting that NTX selectively ablated this correlation among G-allele carriers (Table 2). A similar pattern emerged for VS activation: across all subjects, the correlation was not significant $(r(71)=0.17, p=0.16)$, and it approached significance among G-allele carriers who received placebo $(r(15)=0.43, p=0.09)$ but not among those who received NTX or among A-allele homozygotes. For OFC activation, the correlation was not significant across all subjects $(r(71)=-0.12, p=0.31)$ or in any medication/A118G subgroup.

\section{DAT1 VNTR moderating effects}

DAT1 genotype moderated medication effects on VS and mPFC activation. There was a three-way interaction between medication and A118G and DAT1 genotypes on VS activation $(F(1,63)=4.02, p=0.05)$, such that a two-way interaction between medication and DAT1 genotype was 
Table I Genotype Frequencies and Demographic and Drinking Data for Subjects with Usable Scans

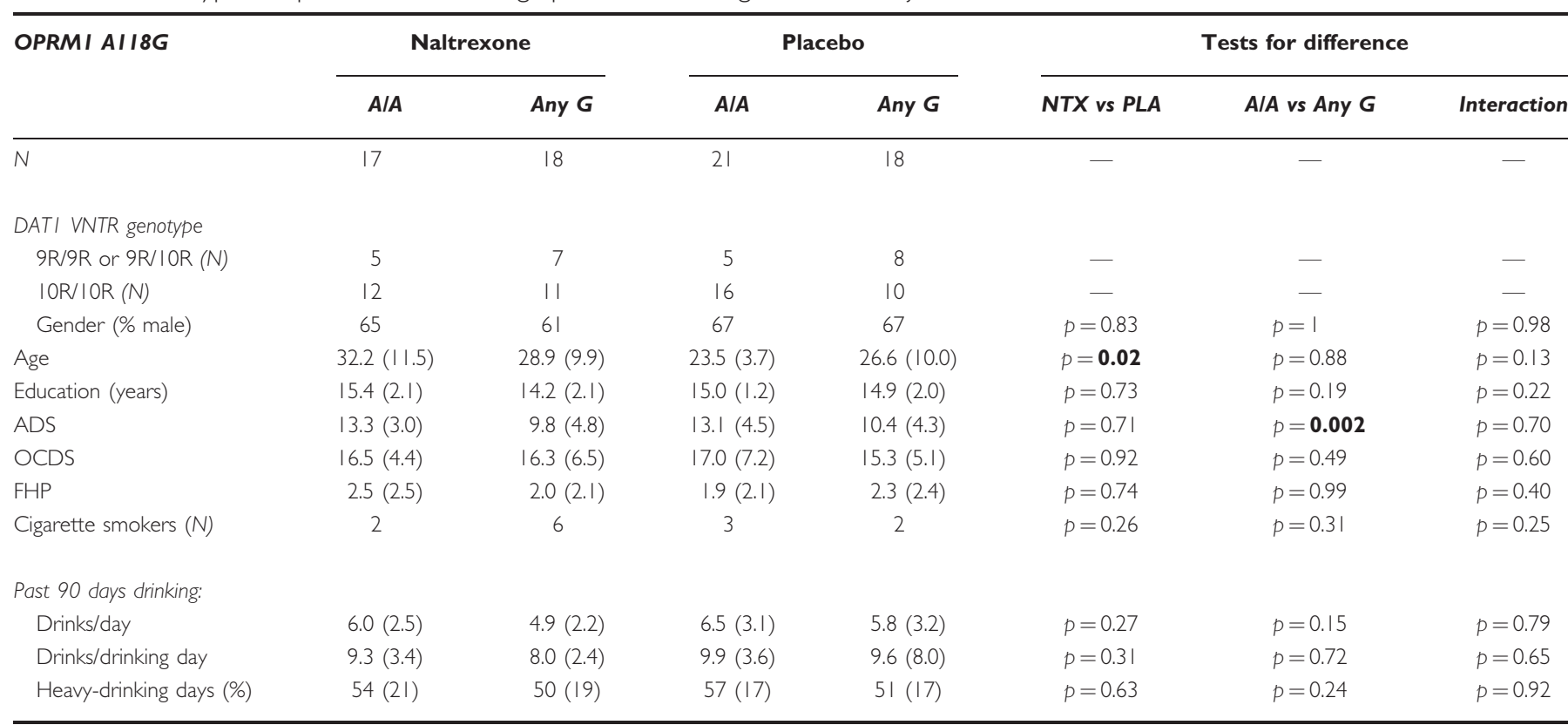

Abbreviations: ADS, Alcohol Dependence Scale; FHP, family history positive for alcoholism (number of first- or second-degree relatives); NTX, naltrexone; OCDS, Obsessive Compulsive Drinking Scale; PLA, placebo.

Unless otherwise indicated, figures are means (standard deviations). Significant differences are in bold.

present only among A118G G-allele carriers (Figure 3). Among G-allele carriers who received NTX, the simple effect of DAT1 genotype was significant, such that 10R-allele homozygotes had less activation than 9R-allele carriers $(F(1$, $63)=5.90, p=0.02$ ). There was no three-way significant interaction between medication, OPRM1 genotype, and DAT1 genotype on mPFC or OFC activation (data not shown). However, there was a two-way interaction between medication and DAT1 genotype on mPFC activation ( $F(1$, $67)=4.32, p=0.04$ ); among subjects who received NTX, the simple effect of DAT1 genotype was significant, such that 10R-allele homozygotes had less activation than 9R-allele carriers $(F(1,67)=4.79, p=0.03)$ (see Figure 3).

\section{DISCUSSION}

These data do not suggest, as previously reported, that NTX or OPRM1 A118G genotype independently affects alcohol cue-elicited brain activation. However, they indicate an interaction between these factors on OFC activation, such that among subjects who received NTX, G-allele carriers had less OFC activation than A-allele homozygotes. Further, these data suggest that NTX effects on cue-elicited activation in the VS and MPFC may be moderated by variation at a VNTR in the DAT1 $3^{\prime}$ untranslated region. The VS finding, in particular, is consistent with the previously reported three-way interaction of NTX and A118G and DAT1 variation on drinking during the subacute NTX treatment period (Anton et al, 2012).

It is unclear why this study did not replicate previously reported main effects of NTX or A118G variation on cueelicited activation (Filbey et al, 2008; Myrick et al, 2008). Subjects in all three studies were similar (young adult heavy drinkers/non-treatment-seeking alcoholics). The current study had more subjects for the NTX vs placebo (35 vs 39 subjects) and A118G A vs G (38 vs 36) comparisons than either previous study, and a power analysis based on our previously reported NTX effect on cue-elicited VS activation (Myrick et al, 2008) estimated $80 \%$ power for detecting main effects or an interaction. Effects in the previous studies were reported at relatively lenient statistical thresholds $(p<0.05$, uncorrected for multiple voxelwise comparisons, although the Filbey study used a large subcortical mask, rather than the whole brain), raising the possibility of Type I error. Alternatively, variance in genes besides OPRM1 and DAT1 that have been reported to affect alcohol cue reactivity (eg, CNR1 (Hutchison et al, 2008), DRD4 (Hutchison et al, 2003)) may have differed between the current study and previous studies. However, as the current study also did not replicate a main effect of sub-acute NTX treatment on drinking (Anton et al, 2012), as both we (Drobes et al, 2003) and others (Davidson et al, 1999; Tidey et al, 2008) have previously reported, some caution should be exercised in interpreting the absence of main effects.

Notwithstanding the absence of NTX or A118G main effects, these factors did interact in their effects on cueelicited OFC activation in the predicted direction (ie, among subjects who received NTX, G-allele carriers had less activation than A-allele homozygotes). OFC is believed to underlie the attribution of salience to stimuli and the evaluation of stimuli as reinforcers or punishers (Kringelbach and Rolls, 2004), and its activation by alcohol cues has been associated with craving (see Schacht et al, 2012, for review). Thus, an NTX by A118G interaction on cue-elicited OFC activation is consistent with previous reports that NTX's effects among G-allele carriers are mediated through reduction of craving (Ray and Hutchison, 
a
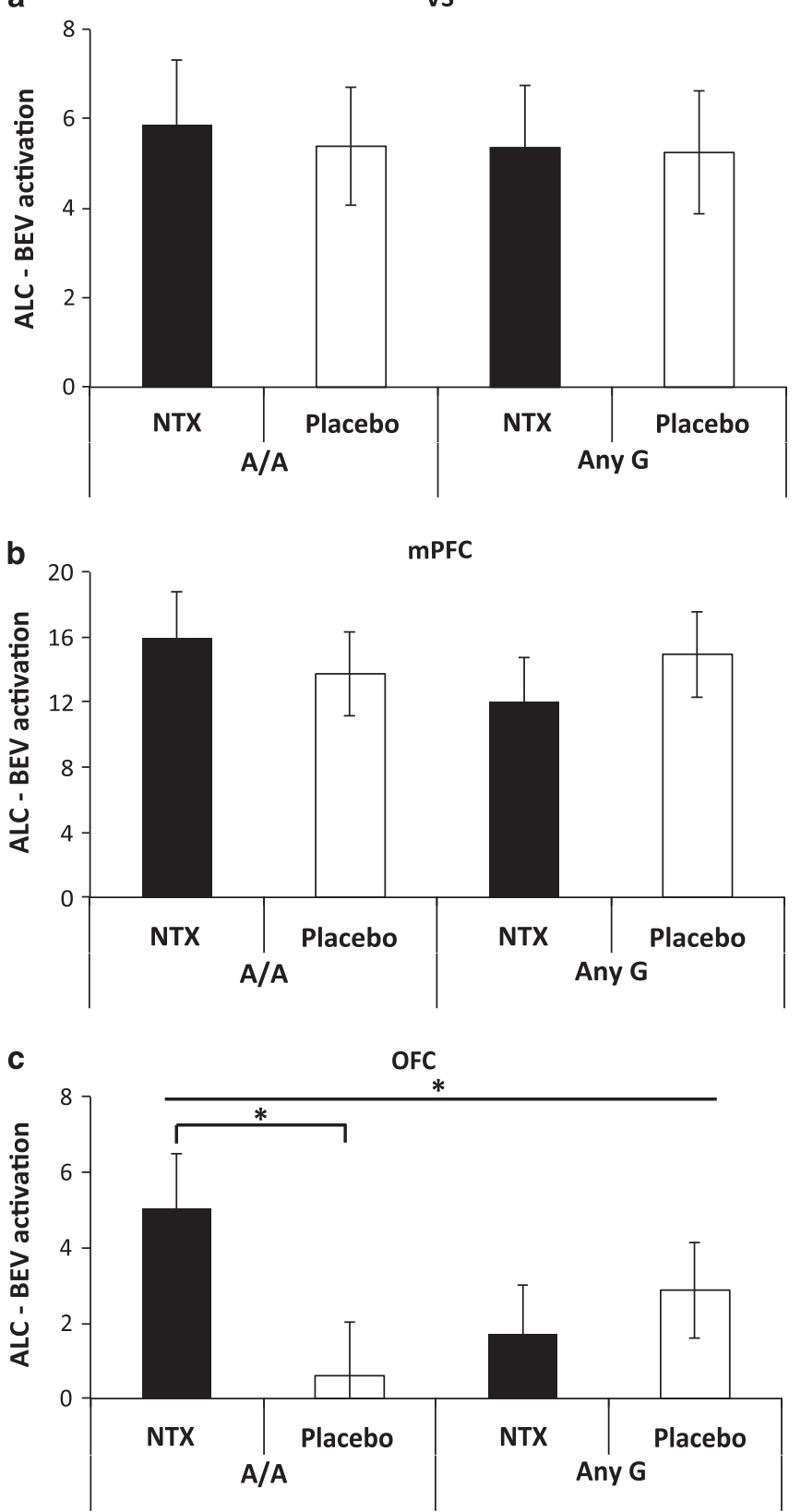

Figure 2 Effects of medication and OPRM / A I I8G genotype on alcohol cue-elicited activation (arbitrary units \pm standard error) in each ROI. There were no main effects of medication or AII8G genotype on activation in any ROI, but these factors interacted in their effects on OFC activation. (a) VS; (b) mPFC; (c) OFC. Horizontal lines indicate significant interactions, and brackets indicate significant simple effects. ${ }^{*} p \leqslant 0.05$.

2007; Ray et al, 2012b). NTX blocks $\mu$-opioid receptors equally across all the brain regions (Weerts et al, 2008), but the greater expression of $\mu$ receptors, relative to $\Delta$ and $\kappa$ receptors, in OFC than in VS and mPFC (Le Merrer et al, 2009) might account for the fact that this interaction was significant only for OFC activation. Although NTX and A118G did not interact in their effects on VS or mPFC activation, NTX did appear to selectively ablate the correlation between drinking during the medication period and activation in these areas among A118G G-allele carriers (ie, among these subjects, this correlation was significant or approached significance in the placebo group, but not the
Table 2 Partial Correlations between Cue-elicited activation and drinks per day During the Medication Period

\begin{tabular}{|c|c|c|c|c|c|}
\hline \multirow[t]{2}{*}{ OPRMIAII8G } & \multicolumn{2}{|c|}{ Naltrexone } & \multicolumn{2}{|c|}{ Placebo } & \multirow[t]{2}{*}{ All Subjects } \\
\hline & $A / A$ & Any $G$ & $A / A$ & Any G & \\
\hline VS & -0.03 & 0.24 & 0.01 & 0.43 & 0.17 \\
\hline $\mathrm{mPFC}$ & -0.15 & 0.13 & -0.09 & $0.51 *$ & 0.18 \\
\hline OFC & -0.27 & 0.15 & -0.19 & -0.01 & -0.12 \\
\hline
\end{tabular}

Abbreviations: mPFC, medial prefrontal cortex; OFC, orbitofrontal cortex; VS, ventral striatum.

All figures are rs, controlling for pre-study drinks per drinking day. $* p \leqslant 05$.
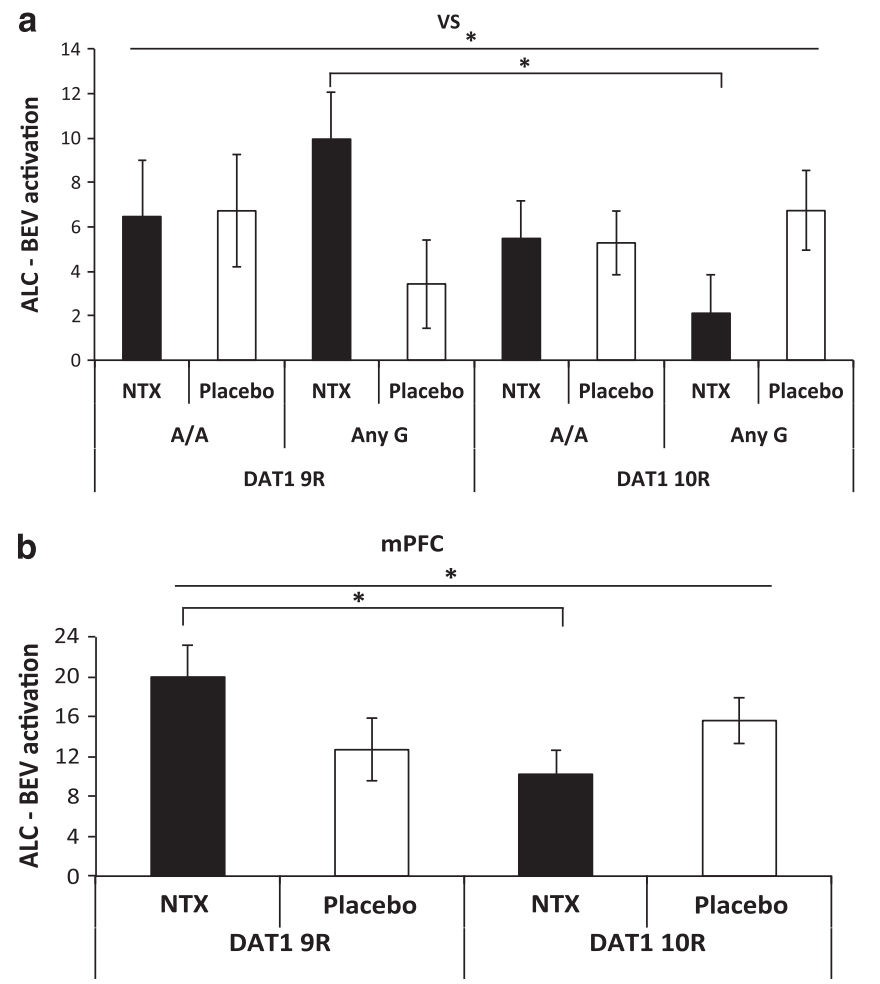

Figure 3 Interactions between medication and OPRMI AII8G and DATI VNTR genotypes on cue-elicited activation (arbitrary units \pm standard error). There was a three-way interaction between medication and AI I8G and DATI genotypes on VS activation, and a two-way interaction between medication and DATI genotype on mPFC activation. (a) VS; (b) mPFC. Horizontal lines indicate significant interactions, and brackets indicate significant simple effects. $* p \leqslant 0.05$.

NTX group). Cue-elicited activation of these areas has also frequently been associated with craving. Therefore, these findings might suggest that these subjects' drinking, while not reduced relative to placebo or A-allele homozygotes, had become less stimulus-bound.

Despite the absence of an NTX by A118G interaction on VS and mPFC activation, the moderating effects of DAT1 VNTR genotype on VS and MPFC activation are intriguing in light of this variant's putative effect on DA function. Cue-elicited activation of these regions was reduced in the NTX group relative to placebo only when subjects were also DAT1 10R-allele-carriers (and, for VS, A118G G-allele carriers). As NTX attenuates alcohol's ability to elevate DA release in VS (Gonzales and Weiss, 1998) and the DAT1 9R allele is believed to predispose greater synaptic 
DA concentration (thereby opposing NTX effects), these findings suggest that NTX might be more effective among individuals who carry the DAT1 10R allele. Consistent with these data, and in support of this interpretation, NTX also more effectively reduced drinking among DAT1 10R carriers who had an A118G G allele and among 9R carriers who lacked a $G$ allele, suggesting an interaction between variation in these genes on NTX effects (Anton et al, 2012).

Human neuroimaging studies of the DAT1 VNTR (Aarts et al, 2010; Dreher et al, 2009; Forbes et al, 2009; Franklin et al, 2009, 2011; Nikolova et al, 2011) have consistently reported that $9 \mathrm{R}$-allele carriers display phenotypes indicative of reduced DAT function and greater striatal synaptic DA availability (ie, greater VS activation elicited by the anticipation and receipt of uncertain monetary reward and by drug cues). However, molecular studies of the functional relevance of this variant, like those of A118G, have been somewhat mixed: in addition to those supporting an association between the 9R allele and loss of DAT function (Fuke et al, 2001; Mill et al, 2002; VanNess et al, 2005), one study has reported no difference in DAT1 mRNA expression between the 9R and 10R alleles (Pinsonneault et al, 2011), and others have suggested that the 10R allele may be associated with loss of function (Inoue-Murayama et al, 2002; Miller and Madras, (2002)). Thus, further study of the functional consequences of variation at this locus, as well as its epistatic interactions with A118G variation, is clearly warranted.

This study had several important strengths and limitations. It is one of the largest clinical experiments to prospectively recruit alcohol-dependent subjects on a genetic basis, randomly assign them to active or placebo medication, and assess them with previously validated drinking and neuroimaging paradigms. However, some of the subgroups for the exploration of three-way interactions were relatively small, especially for DAT1 9R-allele carriers; these findings should be replicated in a larger sample. Additionally, because two scanners were used and this parameter was covaried out of the estimates of cue-elicited activation, variance shared between scanner and medication or genotype groups may have been lost, decreasing power to detect medication or genotype main effects. Finally, no pretreatment scan was conducted, allowing the possibility that the medication effects reported actually reflected preexisting group differences. Our ongoing study of treatment-seeking alcoholics randomized to NTX or placebo on the basis of their A118G genotype includes both pre- and within-treatment scans, and should be helpful in resolving questions about pre-existing differences, as well as those regarding whether the salience of the NTX by A118G interaction depends on subjects' severity of alcohol dependence and/or treatment-seeking status. The current findings have greatest relevance for the non-treatmentseeking population studied here, whose dependence was less severe than in previous studies of the NTX by A118G interaction (eg, Anton et al, 2008; Oslin et al, 2003) and among whom genes affecting DA signaling might be expected to exert greater effects than a more severely dependent population (Koob and Volkow, 2010).

In conclusion, this study suggests that NTX effects on alcohol cue-elicited OFC activation are moderated by OPRM1 A118G variation in a manner consistent with the clinical literature on this variant, and that medication effects on cue-elicited activation in other reward-related regions (VS and $\mathrm{mPFC}$ ) may be affected by a genetic variant that putatively influences dopaminergic signaling, indicating an epistatic interaction. The latter finding should be investigated in other studies of NTX, particularly in those assessing its effects on reward processing and treatment response. Hypothesis-driven, clinically relevant imaging pharmacogenetics research of this nature may allow identification of subgroups that preferentially benefit from treatment for alcohol dependence, and may ultimately lead to more personalized treatment approaches to this disorder.

\section{ACKNOWLEDGEMENTS}

This work was supported by grants from the National Institute on Alcohol Abuse and Alcoholism: P50 AA010761 (the Charleston Alcohol Research Center), T32 AA007474 (to Dr Schacht), and K05 AA017435 (to Dr Anton). Portions were presented in a symposium at the 35th Annual Meeting of the Research Society on Alcoholism (June, 2012, San Francisco, CA).

\section{DISCLOSURE}

Dr Anton reports as being a consultant or on the scientific advisory board for Eli Lilly, GlaxoSmithKline, Alkermes, Lundbeck, and Roche for the past 3 years. Additionally, as part of the Alcohol Clinical Trials Initiative workgroup (ACTIVE), he has received support from Eli Lilly, Schering Plough, Lundbeck, Alkermes, GlaxoSmithKline, Johnson \& Johnson, and Abbott Laboratories. He has also received research contracts/grants from Eli Lilly and Merck. He is a stockholder in Alcomed, which has received Small Business Technology Transfer Research support from NIDA. Dr Myrick reports serving on speakers' bureaus for BristolMyers Squibb and Alkermes. All other authors declare no conflict of interest.

\section{REFERENCES}

Aarts E, Roelofs A, Franke B, Rijpkema M, Fernandez G, Helmich RC et al (2010). Striatal dopamine mediates the interface between motivational and cognitive control in humans: evidence from genetic imaging. Neuropsychopharmacology 35: 1943-1951.

American Psychiatric Association (2000). Diagnostic and Statistical Manual of Mental Disorders 4th edn, text rev. Author: Washington, DC.

Anton RF, Drobes DJ, Voronin K, Durazo-Avizu R, Moak D (2004). Naltrexone effects on alcohol consumption in a clinical laboratory paradigm: temporal effects of drinking. Psychopharmacology (Berl) 173: 32-40.

Anton RF, Moak DH, Latham PK (1996). The obsessive compulsive drinking scale: A new method of assessing outcome in alcoholism treatment studies. Arch Gen Psychiatry 53: 225-231.

Anton RF, Oroszi G, O'Malley S, Couper D, Swift R, Pettinati H et al (2008). An evaluation of mu-opioid receptor (OPRM1) as a predictor of naltrexone response in the treatment of alcohol dependence: results from the Combined Pharmacotherapies and Behavioral Interventions for Alcohol Dependence (COMBINE) study. Arch Gen Psychiatry 65: 135-144.

Anton RF, Voronin KK, Randall PK, Myrick H, Tiffany A (2012). Naltrexone modification of drinking effects in a subacute treatment and bar-lab paradigm: influence of OPRM1 and 
dopamine transporter (SLC6A3) genes. Alcohol Clin Exp Res (e-pub ahead of print).

Barr CS, Chen SA, Schwandt ML, Lindell SG, Sun H, Suomi SJ et al (2010). Suppression of alcohol preference by naltrexone in the rhesus macaque: a critical role of genetic variation at the microopioid receptor gene locus. Biol Psychiatry 67: 78-80.

Benjamin D, Grant ER, Pohorecky LA (1993). Naltrexone reverses ethanol-induced dopamine release in the nucleus accumbens in awake, freely moving rats. Brain Res 621: 137-140.

Boettiger CA, Kelley EA, Mitchell JM, D’Esposito M, Fields HL (2009). Now or later? An fMRI study of the effects of endogenous opioid blockade on a decision-making network. Pharmacol Biochem Behav 93: 291-299.

Bond C, LaForge KS, Tian M, Melia D, Zhang S, Borg L et al (1998). Single-nucleotide polymorphism in the human mu opioid receptor gene alters beta-endorphin binding and activity: possible implications for opiate addiction. Proc Natl Acad Sci U S A 95: 9608-9613.

Chamorro AJ, Marcos M, Miron-Canelo JA, Pastor I, GonzalezSarmiento R, Laso FJ (2012). Association of micro-opioid receptor (OPRM1) gene polymorphism with response to naltrexone in alcohol dependence: a systematic review and meta-analysis. Addict Biol 17: 505-512.

Coller JK, Cahill S, Edmonds C, Farquharson AL, Longo M, Minniti $\mathrm{R}$ et al (2011). OPRM1 A118G genotype fails to predict the effectiveness of naltrexone treatment for alcohol dependence. Pharmacogenet Genomics 21: 902-905.

Davidson D, Palfai T, Bird C, Swift R (1999). Effects of naltrexone on alcohol self-administration in heavy drinkers. Alcohol Clin Exp Res 23: 195-203.

Dreher J-C, Kohn P, Kolachana B, Weinberger DR, Berman KF (2009). Variation in dopamine genes influences responsivity of the human reward system. Proc Natl Acad Sci U S A 106: 617-622.

Drobes DJ, Anton RF, Thomas SE, Voronin K (2003). A clinical laboratory paradigm for evaluating medication effects on alcohol consumption: naltrexone and nalmefene. Neuropsychopharmacology 28: 755-764.

Drobes DJ, Anton RF, Thomas SE, Voronin K (2004). Effects of naltrexone and nalmefene on subjective response to alcohol among non-treatment-seeking alcoholics and social drinkers. Alcohol Clin Exp Res 28: 1362-1370.

Filbey FM, Ray L, Smolen A, Claus ED, Audette A, Hutchison KE (2008). Differential neural response to alcohol priming and alcohol taste cues is associated with DRD4 VNTR and OPRM1 genotypes. Alcohol Clin Exp Res 32: 1113-1123.

First MB, Spitzer RL, Gibbon M, Williams JBW (2002). Structured Clinical Interview for DSM-IV-TR Axis I Disorders Research Version, Non-patient EditionBiometrics Research, New York State Psychiatric Institute: New York.

Forbes EE, Brown SM, Kimak M, Ferrell RE, Manuck SB, Hariri AR (2009). Genetic variation in components of dopamine neurotransmission impacts ventral striatal reactivity associated with impulsivity. Mol Psychiatry 14: 60-70.

Franklin TR, Lohoff FW, Wang Z, Sciortino N, Harper D, Li Y et al (2009). DAT genotype modulates brain and behavioral responses elicited by cigarette cues. Neuropsychopharmacology 34: 717-728.

Franklin TR, Wang Z, Li Y, Suh JJ, Goldman M, Lohoff FW et al (2011). Dopamine transporter genotype modulation of neural responses to smoking cues: confirmation in a new cohort. Addict Biol 16: 308-322.

Fuke S, Suo S, Takahashi N, Koike H, Sasagawa N, Ishiura S (2001). The VNTR polymorphism of the human dopamine transporter (DAT1) gene affects gene expression. Pharmacogenom J 1: $152-156$.

Gelernter J, Gueorguieva R, Kranzler HR, Zhang H, Cramer J, Rosenheck $\mathrm{R}$ et al (2007). Opioid receptor gene (OPRM1, OPRK1, and OPRD1) variants and response to naltrexone treatment for alcohol dependence: results from the VA Cooperative Study. Alcohol Clin Exp Res 31: 555-563.

Gonzales RA, Job MO, Doyon WM (2004). The role of mesolimbic dopamine in the development and maintenance of ethanol reinforcement. Pharmacol Ther 103: 121-146.

Gonzales RA, Weiss F (1998). Suppression of ethanol-reinforced behavior by naltrexone is associated with attenuation of the ethanol-induced increase in dialysate dopamine levels in the nucleus accumbens. J Neurosci 18: 10663-10671.

Heinz A, Goldman D, Jones DW, Palmour R, Hommer D, Gorey JG et al (2000). Genotype influences in vivo dopamine transporter availability in human striatum. Neuropsychopharmacology 22: 133-139.

Heinz A, Siessmeier T, Wrase J, Hermann D, Klein S, Grüsser SM et al (2004). Correlation between dopamine $\mathrm{D}(2)$ receptors in the ventral striatum and central processing of alcohol cues and craving. Am J Psychiatry 161: 1783-1789.

Hutchison KE, Haughey H, Niculescu M, Schacht J, Kaiser A, Stitzel J et al (2008). The incentive salience of alcohol: translating the effects of genetic variant in CNR1. Arch Gen Psychiatry 65: 841-850.

Hutchison KE, Wooden A, Swift RM, Smolen A, McGeary J, Adler L et al (2003). Olanzapine reduces craving for alcohol: a DRD4 VNTR polymorphism by pharmacotherapy interaction. Neuropsychopharmacology 28: 1882-1888.

Inoue-Murayama $\mathrm{M}$, Adachi $\mathrm{S}$, Mishima $\mathrm{N}$, Mitani $\mathrm{H}$, Takenaka $\mathrm{O}$, Terao $\mathrm{K}$ et al (2002). Variation of variable number of tandem repeat sequences in the 3'-untranslated region of primate dopamine transporter genes that affects reporter gene expression. Neurosci Lett 334: 206-210.

Kang AM, Palmatier MA, Kidd KK (1999). Global variation of a 40bp VNTR in the 3'-untranslated region of the dopamine transporter gene (SLC6A3). Biol Psychiatry 46: 151-160.

Koob GF, Volkow ND (2010). Neurocircuitry of addiction. Neuropsychopharmacology 35: 217-238.

Kranzler HR, Van Kirk J (2001). Efficacy of naltrexone and acamprosate for alcoholism treatment: a meta-analysis. Alcohol Clin Exp Res 25: 1335-1341.

Kringelbach ML, Rolls ET (2004). The functional neuroanatomy of the human orbitofrontal cortex: evidence from neuroimaging and neuropsychology. Prog Neurobiol 72: 341-372.

Le Merrer J, Becker JA, Befort K, Kieffer BL (2009). Reward processing by the opioid system in the brain. Physiol Rev 89: 1379-1412.

McGeary JE, Monti PM, Rohsenow DJ, Tidey J, Swift R, Miranda R Jr. (2006). Genetic moderators of naltrexone's effects on alcohol cue reactivity. Alcohol Clin Exp Res 30: 1288-1296.

Mill J, Asherson P, Browes C, D'Souza U, Craig I (2002). Expression of the dopamine transporter gene is regulated by the 3' UTR VNTR: Evidence from brain and lymphocytes using quantitative RT-PCR. Am J Med Genet 114: 975-979.

Miller GM, Madras BK (2002). Polymorphisms in the 3'-untranslated region of human and monkey dopamine transporter genes affect reporter gene expression. Mol Psychiatry 7: 44-55.

Myrick H, Anton RF, Li X, Henderson S, Drobes D, Voronin K et al (2004). Differential brain activity in alcoholics and social drinkers to alcohol cues: relationship to craving. Neuropsychopharmacology 29: 393-402.

Myrick H, Anton RF, Li X, Henderson S, Randall PK, Voronin K (2008). Effect of naltrexone and ondansetron on alcohol cueinduced activation of the ventral striatum in alcohol-dependent people. Arch Gen Psychiatry 65: 466-475.

Myrick H, Li X, Randall PK, Henderson S, Voronin K, Anton RF (2010). The effect of aripiprazole on cue-induced brain activation and drinking parameters in alcoholics. $J$ Clin Psychopharmacol 30: 365-372.

Nikolova YS, Ferrell RE, Manuck SB, Hariri AR (2011). Multilocus genetic profile for dopamine signaling predicts ventral striatum reactivity. Neuropsychopharmacology 36: 1940-1947. 
O’Malley SS, Krishnan-Sarin S, Farren C, Sinha R, Kreek MJ (2002). Naltrexone decreases craving and alcohol self-administration in alcohol-dependent subjects and activates the hypothalamopituitary-adrenocortical axis. Psychopharmacology (Berl) 160: 19-29.

Oslin DW, Berrettini W, Kranzler HR, Pettinati H, Gelernter J, Volpicelli JR et al (2003). A functional polymorphism of the muopioid receptor gene is associated with naltrexone response in alcohol-dependent patients. Neuropsychopharmacology 28: 1546-1552.

Pinsonneault JK, Han DD, Burdick KE, Kataki M, Bertolino A, Malhotra AK et al (2011). Dopamine transporter gene variant affecting expression in human brain is associated with bipolar disorder. Neuropsychopharmacology 36: 1644-1655.

Ramchandani VA, Umhau J, Pavon FJ, Ruiz-Velasco V, Margas W, Sun $\mathrm{H}$ et al (2011). A genetic determinant of the striatal dopamine response to alcohol in men. Mol Psychiatry 16: 809-817.

Ray LA, Barr CS, Blendy JA, Oslin D, Goldman D, Anton RF (2012a). The role of the Asn40Asp polymorphism of the mu opioid receptor gene (OPRM1) on alcoholism etiology and treatment: a critical review. Alcohol Clin Exp Res 36: 385-394.

Ray LA, Bujarski S, Chin PF, Miotto K (2012b). Pharmacogenetics of naltrexone in asian americans: a randomized placebo-controlled laboratory study. Neuropsychopharmacology 37: 445-455.

Ray LA, Hutchison KE (2004). A polymorphism of the mu-opioid receptor gene (OPRM1) and sensitivity to the effects of alcohol in humans. Alcohol Clin Exp Res 28: 1789-1795.

Ray LA, Hutchison KE (2007). Effects of naltrexone on alcohol sensitivity and genetic moderators of medication response: a double-blind placebo-controlled study. Arch Gen Psychiatry 64: 1069-1077.

Rosner S, Hackl-Herrwerth A, Leucht S, Vecchi S, Srisurapanont M, Soyka M (2010). Opioid antagonists for alcohol dependence. Cochrane Database Syst Rev CD001867.

Schacht JP, Anton RF, Myrick H (2012). Functional neuroimaging studies of alcohol cue reactivity: a quantitative meta-analysis and systematic review. Addict Biol (e-pub ahead of print).

Schacht JP, Anton RF, Randall PK, Li X, Henderson S, Myrick H (2011). Stability of fMRI striatal response to alcohol cues: A hierarchical linear modeling approach. NeuroImage 56: 61-68.

Schwandt ML, Lindell SG, Higley JD, Suomi SJ, Heilig M, Barr CS (2011). OPRM1 gene variation influences hypothalamic-pitui- tary-adrenal axis function in response to a variety of stressors in rhesus macaques. Psychoneuroendocrinology 36: 1303-1311.

Skinner HA, Allen BA (1982). Alcohol dependence syndrome: measurement and validation. J Abnorm Psychol 91: 199-209.

Smith SM, Jenkinson M, Woolrich MW, Beckmann CF, Behrens TE, Johansen-Berg $\mathrm{H}$ et al (2004). Advances in functional and structural MR image analysis and implementation as FSL. NeuroImage 23(Suppl 1): S208-S219.

Sobell LC, Sobell MB (1992). Timeline follow-back: a technique for assessing self-reported alcohol consumption. In: Allen JP, Litten RZ (eds). Measuring Alcohol Consumption: Psychosocial and Biochemical Methods. Humana Press: Totowa, NJ, pp 41-72.

Stritzke WG, Breiner MJ, Curtin JJ, Lang AR (2004). Assessment of substance cue reactivity: advances in reliability, specificity, and validity. Psychol Addict Behav 18: 148-159.

Sullivan JT, Sykora K, Schneiderman J, Naranjo CA, Sellers EM (1989). Assessment of alcohol withdrawal: the revised clinical institute withdrawal assessment for alcohol scale (CIWA-Ar). $\mathrm{Br}$ J Addict 84: 1353-1357.

Tidey JW, Monti PM, Rohsenow DJ, Gwaltney CJ, Miranda R Jr., McGeary JE et al (2008). Moderators of naltrexone's effects on drinking, urge, and alcohol effects in non-treatment-seeking heavy drinkers in the natural environment. Alcohol Clin Exp Res 32: $58-66$.

VanNess SH, Owens MJ, Kilts CD (2005). The variable number of tandem repeats element in DAT1 regulates in vitro dopamine transporter density. BMC Genet 6: 55.

Weerts EM, Kim YK, Wand GS, Dannals RF, Lee JS, Frost JJ et al (2008). Differences in delta- and mu-opioid receptor blockade measured by positron emission tomography in naltrexonetreated recently abstinent alcohol-dependent subjects. Neuropsychopharmacology 33: 653-665.

Weerts EM, McCaul ME, Kuwabara H, Yang X, Xu X, Dannals RF et al (2012). Influence of OPRM1 Asn40Asp variant (A118G) on [11C]carfentanil binding potential: preliminary findings in human subjects. Int J Neuropsychopharmacol 1-7.

Yoshimoto K, McBride WJ, Lumeng L, Li TK (1992). Ethanol enhances the release of dopamine and serotonin in the nucleus accumbens of HAD and LAD lines of rats. Alcohol Clin Exp Res 16: 781-785.

Zhang Y, Wang D, Johnson AD, Papp AC, Sadee W (2005). Allelic expression imbalance of human mu opioid receptor (OPRM1) caused by variant A118G. J Biol Chem 280: 32618-32624. 